\title{
Systematic literature review on adjustable robust counterpart for internet shopping optimization problem
}

\author{
Mahrudinda $^{a^{*}}$, Diah Chaerani ${ }^{\mathrm{b}}$ and Endang Rusyaman ${ }^{\mathrm{b}}$
}

${ }^{a}$ Master of Mathematics Student, Faculty of Mathematics and Natural Sciences, Universitas Padjadjaran, Sumedang, Indonesia ${ }^{b}$ Department of Mathematics, Faculty of Mathematics and Natural Sciences, Universitas Padjadjaran, Sumedang, Indonesia

\section{H R O N I C L E A B S T R A C T}

Article history:

Received: June 20, 2021

Received in revised format:

September 20, 2021

Accepted: November 17, 2021

Available online: November 17, 2021

Keywords:

Optimization

Internet Shopping Optimization

Problem

Internet Shopping Online Problem

Bibliometric Analysis

Prisma Analysis

Adjustable Robust Counterpart

\begin{abstract}
Internet Shopping Optimization Problem (ISOP) is the application of optimization to online shopping activities of all complexity. The ISOP is useful for consumers in minimizing the cost of purchasing goods. This paper presents a bibliometric analysis of peer-reviewed papers based on ISOP topics by utilizing the $\mathrm{R}$ application program in the mapping. Overall, 101 papers ( 233 authors) in the Scopus database have used ISOP topics with research growth of $11.61 \%$ annually. The researcher presents a network of citations from productive authors, the impact of research, trends in terms that have been used, and shows a collaborative network of citations. Finally, the researcher presents the thematic analysis of the papers that apply the ISOP as a research topic and shows how the research forms clusters based on analytical solutions and numerical simulations that generate suggestions in finding the latest topics in the ISOP study. Another target for this paper is to produce review analysis results through Preferred Reporting Items for Systematic reviews and Meta Analyses (PRISMA). Through bibliometric and PRISMA analysis, it was found that the latest method in completing ISOP optimization is the ARC method. The ARC method in the ISOP is still little published among researchers in the world.
\end{abstract}

\section{Introduction}

Smartphone users continue to grow from time to time in line with the increase in people's online shopping activities. The rise of online shopping activities based on the internet has led to new studies in the field of optimization research. The research is optimization on (ISOP). Research that examines online shopping has continued to increase in the last 10 years. In total, 101 papers have been published in the Google Scholar and Scopus databases. The development of research on topics related to ISOP from year to year continues to increase. The increase in the number of studies indicates that the existing paradigm in the ISOP is increasingly complex and broad, resulting in researchers' interest in discussing it. Based on the search, there is the first research publication entitled Tabu Search Part I written by Glover (1989) in the ORSA Journal on Computing in 1989. The paper presents the basic principles underlying taboo search as a way to solve combinatorial optimization problems. Tabu Search is an efficient way of dealing with classic problems such as traveling salesman optimization and graph coloring problems. Furthermore, in the last 10 years Tabu Search has been used to complete solutions for ISOP optimization. ISOP is an optimization topic in online shopping activities that minimizes purchase costs with all their complexities. Research on the topic of ISOP continues to emerge and experience good development when viewed from a variety of studies. The most recent method used in dealing with ISOP is the Adjustable Robust Counterpart (ARC) method (Chaerani et al., 2021). Referring to

* Corresponding author.

E-mail address: mahrudinda19001@mail.unpad.ac.id (Mahrudinda)

(C) 2022 by the authors; licensee Growing Science, Canada. doi: $10.5267 /$ j.ijdns.2021.11.006 
the research of Chaerani et al. (2021), that the ISOP with a model involving uncertainty parameters can be considered as a Maximum Flow Problem with Circular Demand (MFP-CD), which assumes the uncertainty problem into a polyhedral set.

This research uses a bibliometric analysis method that collects ISOP-themed papers. The next section will describe the materials and methods used for comprehensive analysis in this research. Then, in Section 3, the researcher summarizes the data of all the papers on the ISOP, including the PRISMA analysis, a summary of scientists working in this field, a summary of the most productive researchers and their collaborations, a citation pattern that shows the impact of the authors, summary of keywords and their relevance to other topics, research topic trends, and finally the state of the art ISOP topics are shown. The relationship with other topics presented, aims to find a research gap that can be used as a novelty in making further research. The last section, Section 5, is the closing section in the form of conclusions and suggestions that can reflect this research.

\section{Materials}

\subsection{Internet Shopping Online Optimization Model}

The simple ISOP model was first discussed by Błazewicz et al. (2010), who studied optimization by minimizing online shopping costs. Minimized costs based on the purchase price and delivery costs of 6 types of books available from 6 online stores. The purchase price and the cost of delivery of the goods are modeled in a single objective function. The method used in determining the best solution in this research, namely Shop-Enum \& Product-Enum Algorithm. Then, Chung (2017) developed an ISOP model that minimizes costs (including the price of goods and their costs) and minimizes delivery time. The cost function and delivery cost are shown in two objective functions, which are as follows.

$$
\begin{aligned}
& \min \sum_{i} \sum_{j} p_{i j} x_{i j}+\sum_{j} f_{j} w_{j}, \\
& \min \max _{i, j} d_{i j} x_{i j} \\
& \text { s.t } \sum_{j} x_{i j}=1, \forall i=1, \ldots, n, \\
& \sum_{j} x_{i j} \leq n w_{j}, j=1, \ldots, m, \\
& x_{i j}, w_{i j} \in\{0,1\} .
\end{aligned}
$$

The variable becomes a binary decision variable whose value is one if product $i$ is selected from Store $j$, and when the value is zero, then the product is not selected to be purchased. The variable becomes a binary decision variable that represents the presence or absence of delivery costs in store $j$. The objective function (1) is to minimize costs in the form of product prices and delivery costs. The objective function (2) means that it will minimize the delivery time of all products. Constraint (3), means that all products to be purchased must be selected from available stores. Constraint (4), shows the amount of delivery costs is fixed on the purchase of several products in the same store. Constraint (5), meaning that the decision variable is binary.

\subsection{Adjustable Robust Counterpart Methodology}

Robust Optimization (OR) is a method to find a solution to the problem of Robust optimization of data uncertainty in parameters, where the uncertainty exists in an indeterminate set (Ben-Tal \& Nemirovski, 2002). Most research on OR focuses on static settings, where all decisions have to be made beforehand into the actual realization of indeterminate data. Chen and Zhang (2009) call this uncertainty as primitive uncertainty. The uncertainty arises when a dynamic and diverse data will be estimated. The data of uncertainty is for example data on estimated number of requests, travel time, production costs and various other data estimates.

Bertsimas and Tsitsiklis (1997) provide a general model of the linear optimization problem as follows.

$$
\min _{x}\left\{c^{T} x: A x \leq b\right\}
$$

where $c \in \mathbb{R}^{n}, x \in \mathbb{R}^{n}, A \in M_{m, n}(\mathbb{R}), b \in \mathbb{R}^{m}$.

Next, given the general indeterminate form of the linear optimization problem in Eq. (6). Indeterminate general form of linear optimization in Eq. (6) is obtained by assuming all parameters $(c, A, b)$ are not known with certainty (indeterminate), but are in an indefinite set of primitives U. Primitive in this case means that it has not been determined what the $\mathcal{U}$ set is. Based on 
the existence of these primitive sets, Ben-Tal et al. (2009) formulate the following form Eq. (6) to be Eq. (7).

$$
\min _{x}\left\{c^{T} x: A x \leq b \mid(c, A, b) \in \mathcal{U}\right\}
$$

The assumptions about the Robust optimization form are described as follows:

A.1 All decisions on the variable $x \in \mathbb{R}^{n}$ represent "here and now" decisions. That is, all decision variables are decided simultaneously before the actual data appears.

A.2 The decision maker is solely responsible for the consequences of the decision to be made when the parameters are in the primitive indeterminate set $\mathcal{U}$.

A.3 Constraints contained in Robust Optimization problems are "hard". That is, all existing constraints must not be violated even if the parameters used are in the primitive indeterminate set $\mathcal{U}$.

In addition to these basic assumptions, without losing their generality, in the study by Yanıkoğlu et al. (2019) it is assumed that the objective function is definite, the constraint with a definite right side, $\mathcal{U}$ is compact and convex, and the uncertainty is defined as constraint-wise. The four assumptions above are further described in the following explanation:

E.1 Suppose the objective coefficient $(c)$ is indeterminate and (say) this coefficient is in the uncertainty set $C$ then,

$$
\min _{x} \quad \max _{c \in C^{(}}\left\{c^{T} x: A x \leq b \quad \forall A, b \in \mathcal{U}\right\}
$$

Then raise an additional variable $t \in R$, the problem can be reformulated so that it is equivalent to:

$$
\min _{x, t}\left\{t: c^{T} x-t \leq 0 \forall c \in C, A x \leq b \forall A \in \mathcal{U}\right\}
$$

which is the objective function to be definite.

E.2 Parameters on the right side of $\mathrm{b}$ are deterministic. If there is uncertainty on the right-hand side of the parameter, then the problem can be formed in such a way that the uncertainty does not exist on the right-hand side but appears in the constraint function.

According to the model in problem (8), there is uncertainty in the right-hand side parameter $b$. Next, add the variable $x_{n+1}$ on the right hand side, where $x_{n+1}=1$, so we get:

$$
\begin{aligned}
& \min _{x, t}\left\{t: c^{T} x-t \leq 0 \quad \forall c \in C, A x \leq b x_{n+1}, x_{n+1}=1 \forall A \in \mathcal{U}\right\}, \\
& \min _{x, t}\left\{t: c^{T} x-t \leq 0 \quad \forall c \in C, A x-b x_{n+1} \leq 0, x_{n+1}=1 \forall A \in \mathcal{U}\right\},
\end{aligned}
$$

it can be seen that the right hand side of problem (11) no longer contains uncertainty.

E.3 The set of uncertainty $\mathcal{U}$ is a set of convex hull which is $\operatorname{symbolized~"} \operatorname{conv}(\mathcal{U})$ ". $\operatorname{Conv}(\mathcal{U})$ is the smallest convex set containing $\mathcal{U}$, so that the indeterminate parameter appears linearly within the constraint.

E.4 Robustness to $\mathcal{U}$ can be formulated constraint-wise. That is, the robustness of the robust optimization problem can be seen in each constraint.

Based on the assumptions of E.1, E.2, E.3, and E4 it can be concluded that the model of an indeterminate linear optimization problem can always be formed into a definite linear optimization problem that only contains uncertainty in the constraint function only. These assumptions are used in the Robust Optimization approach to eliminate uncertainty in uncertain problems so that a single deterministic problem is obtained, which is called Robust Counterpart.

Working with assumptions E.1 and E.2, then all the uncertainties that exist in the model can be collected in the constraint matrix $A$. Therefore, all Robust Optimization problems can be reformulated into:

$$
\min _{x}\left\{c^{T} x: A x \leq b \mid A \in \mathcal{U}\right\}
$$

where $x \in \mathbb{R}^{n}, b \in \mathbb{R}^{m}, \mathcal{U}$ is a primitive indefinite set and $A$ is a matrix of size $(m \times n), A \in \mathcal{U}$. If we assume $c \in \mathbb{R}^{m}$ and $b \in \mathbb{R}^{m}$ are definite, then reformulation (12) is generally referred to as Robust Counterpart (RC), which is formulated as follows: 


$$
\min _{x}\left\{c^{T} x: A(\zeta) x \leq b \mid \zeta \in Z\right\}
$$

where $A(\zeta)$ is the affine function and $Z \subset \mathbb{R}^{L}$ represents the user-defined set of primitive uncertainties. $A$ solution $x \in \mathbb{R}^{n}$ is said to be robust feasible if it satisfies the indeterminate constraint $[A(\zeta) x \leq b]$ for all realizations of $\zeta \in Z$. Considering the uncertainty assumption in the constraint-wise Robust Optimization according to E.4, the problem model in (13) can be focused on a single constraint. A single constraint of the problem (13) can be expressed in Eq. (14) as follows:

$$
(a+P \zeta)^{T} x \leq b, \forall \zeta \in \mathcal{Z}
$$

where $(a+P \zeta)$ is an affine function over the primitive indeterminate parameter, $\zeta \in \mathcal{Z}, a \in \mathbb{R}^{n}$, and $P \in M_{n, L}(\mathbb{R})$.

Multi-stage optimization modeling on the first assumption [A1] of the OR paradigm, i.e. the decision is here-and-now. For example, the issue of the number to be produced by a factory next month is not a here-and-now decision, but a wait-and-see decision which will be decided based on the number of goods sold this month. Therefore, some decision variables can be adjusted at a later time according to a decision rule, which is a function of (partially or completely) the uncertainty of the data. These problems are included in the adjustable $\mathrm{RC}$ with the following formulation:

$$
\min _{x, y}\left\{c^{T} x: A(\zeta) x+B y(\zeta) \leq b \quad \forall \zeta \in Z\right\}
$$

where $x \in \mathbb{R}^{n}$ is the first-step here-and-now decision made before $\zeta \in \mathbb{R}^{L}$ is realized. Next, $y \in \mathbb{R}^{k}$ represents the secondstage wait-and-see decision that can be adjusted according to the actual data, and $B \in \mathbb{R}^{m \times k}$ represents the specified coefficient matrix. According to Yanıkoğlu et al. (2019) the following the ARC procedure in its application.

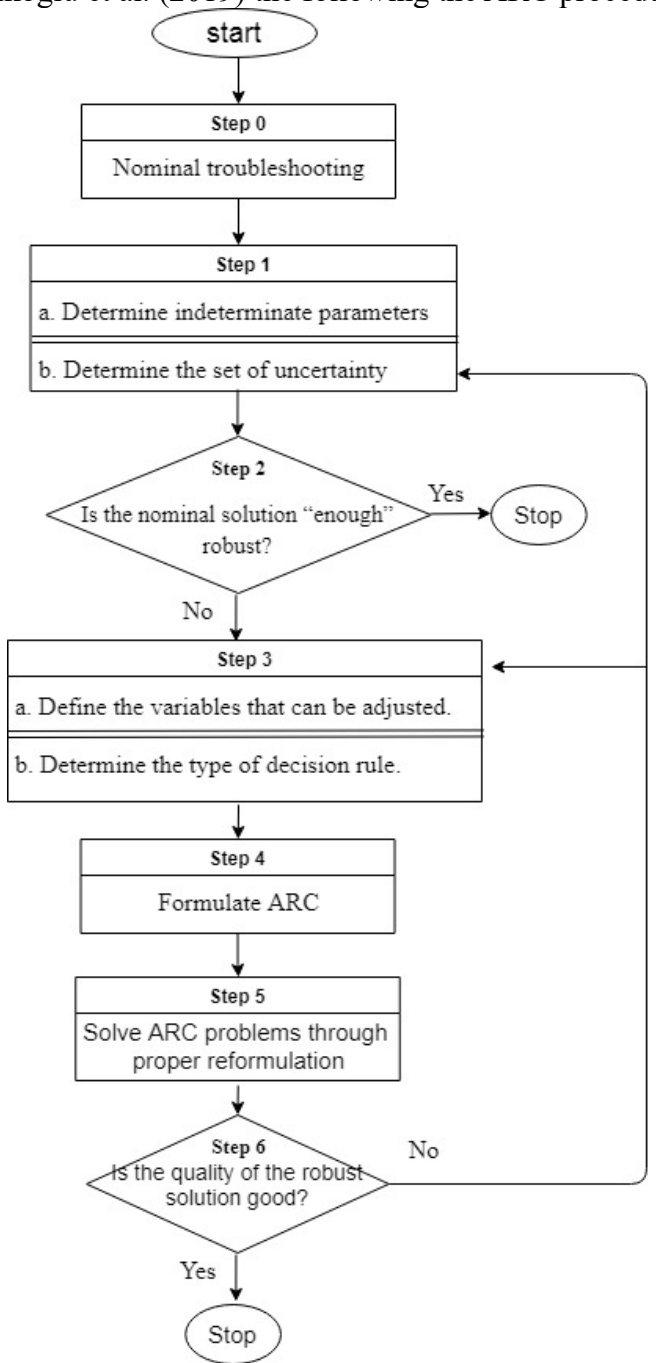

Fig. 1. ARC implementation procedure 
Since it is difficult to optimize more than one set of functions, the RO field began to use parameterized function optimization, where the search space is often limited to the following affine functions according to (Yanıkoğlu et al., 2019) and discussed in (Chaerani et al., 2021):

$$
y(\zeta)=y^{0}+Q \zeta
$$

Parameters $y^{0} \in \mathbb{R}^{k}$ and $Q \in \mathbb{R}^{k \times L}$ decision rule coefficients that must be optimized. Furthermore, by substituting equation (16) into the form (15), the Affinely Adjustable Robust Counterpart (AARC) form is obtained as follows:

$$
\min _{\left.x, y^{0}, Q^{\{} x: A(\zeta) x+B y^{0}+B Q \zeta \leq b \quad \forall \zeta \in Z\right\}}
$$

AARC are linear in the optimization variables and indeterminate parameters. The optimal solution $\left(x, y^{0}, Q\right)$ contains the decision variable $x$ (here-and-now) which can be implemented immediately, and also the coefficient for calculating $y(\zeta)$ according to (16) as soon as $\zeta$ is observed.

\subsection{Adjustable Robust Counterpart for Internet Shopping Online Problem}

The most recent ISOP was then discussed by (Chaerani et al., 2021) who provided further solutions to the ISOP problem from Chung's research (Chung, 2017). Chaerani et al. (2021) used the adjustable robust counterpart (ARC) method in formulating the objective function into several constraints. The complete formulation of the ISOP model from the research of (Chaerani et al., 2021) is:

$$
\begin{aligned}
& \min \sum_{i} \sum_{j} p_{i j} x_{i j}+\sum_{j} f_{j} w_{j}, \\
& s . t \sum_{j} x_{i j}=1, \forall i=1, \ldots, n, \\
& \sum_{j} x_{i j} \leq n w_{j}, j=1, \ldots, m, \\
& d_{i j} x_{i j} \leq t, i=1, \ldots, n, \\
& \bar{d}_{\max }+d_{x}^{T} y_{x}-t \geq 0, \\
& A z=0, \\
& z_{i j}-\bar{d}_{i j} w_{i j}-p_{i j}^{T} y_{k} \leq 0, \forall i, j, k \\
& D_{k}^{T} y_{k}=p_{i j}^{T} w_{i j}, \\
& D_{k}^{T} y_{k}=Q, \\
& w_{i j}=1, \\
& y_{z}, y_{k} \geq 0, \\
& z_{i j} \geq 0, \forall i, j, t \geq 0, \\
& x_{i j}, w_{i j} \in\{0,1\} .
\end{aligned}
$$

Constraints (21)-(30), are formulated from the objective function (2) which contains an element of uncertainty. The uncertainty problem is seen as the Maximum Flow Problem with Circular Demand (RMFP-CD). The uncertainty problem of maximum delivery cost $\left(d_{\max }\right)$ is categorized as a polyhedral uncertainty set (for more details, see (Chaerani et al., 2021)). The completion of the ISOP model with the ARC involves an integer variable y, so the model can be solved as a two-stage robust optimization problem. One alternative procedure for solving two-stage robust linear integer programming problems is the Benders Decomposition method (Billionnet et al., 2014).

\section{Methods}

The literature review was carried out using the Preferred Reporting Items for Systematic reviews and Meta Analysis (PRISMA) as discussed by Moher et al. (2009). PRISMA provides a structured and systematic guide in conducting a systematic literature review (Stovold et al., 2014). The next analysis is using a complete bibliographic analysis of all the papers ever published on ISOP. The author only searches for research in the form of peer-reviewed journal papers by searching the Google Scholar and Scopus databases using the open source Publish or Perish application. Search all papers including search terms using quotation marks to ensure that all terms are searched simultaneously. The search keywords used are "Internet Shopping Optimization" OR "Internet Shopping Optimization" OR "Internet Shopping Online". The analysis 
includes all titles and abstracts of English papers. After the search is complete, all metadata is saved in bibtex or CSV format for use in the analysis phase. Then the data were analyzed using the open source R Programming software (Urbanek et al., 2014) using the bibliometrix package (Aria \& Cuccurullo, 2017). The package is able to produce a lot of bibliographic information for each paper so that it can be analyzed and manipulated for scientific mapping (Aria \& Cuccurullo, 2017; Templeton, 2020).

\section{Results}

\subsection{PRISMA Analysis}

The first stage in PRISMA is identification, which is a search for research articles published in peer-review on the Scopus and Google Scholar databases using the open source Publish or Perish application. The search keywords used are "Internet Shopping Optimization" OR "Internet Shopping Optimization" OR "Internet Shopping Online". The second stage is Screening, the articles obtained are then selected according to four criteria, namely: (1) full-text articles (peer-reviewed papers), (2) article manuscripts in English, and (3) article manuscripts published by journals. Furthermore, at the Eligibility stage, there is a selection of articles based on topics that match the desired research criteria. This stage is carried out twice in succession, namely selection of eligibility for the title and abstract, then selection of eligibility for full-text articles as a whole in each article. So that in the last stage, namely the included stage, a number of articles were obtained that will be used as literature reviews. The summary of the PRISMA flowchart on the ISOP topic is shown in the following figure.

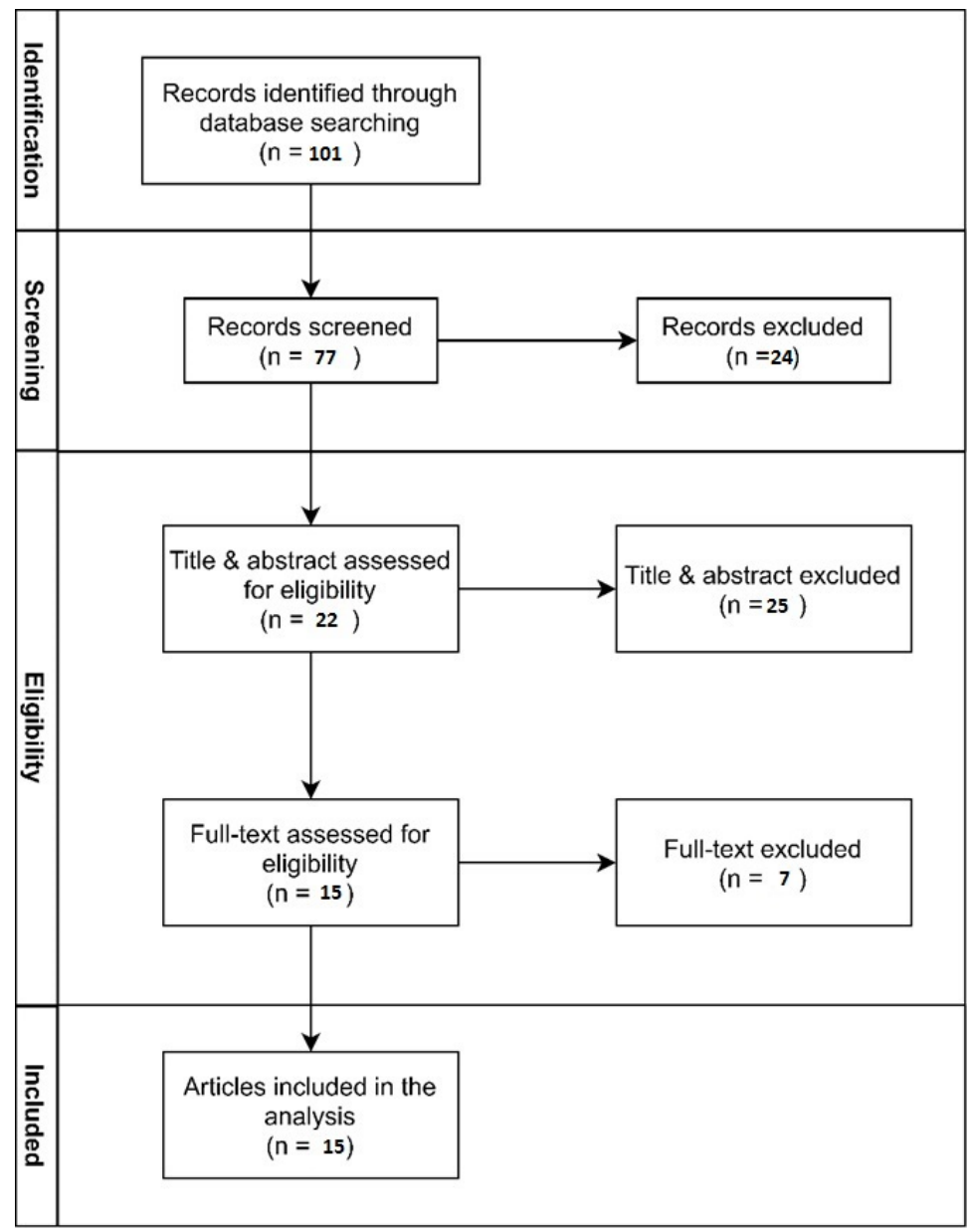

Fig. 2. PRISMA Flowchart of ISOP model

Through a literature search with the keyword ISOP, 101 articles were identified. Then, the 101 identified articles were selected at the screening stage. At the screening stage, 24 articles were eliminated because they did not qualify as English articles, as peer-reviewed articles, and as articles published by journals. The selection at the screening stage leaves 77 articles which will then be selected based on the Eligibility stage. Eligibility for titles and abstracts were selected as many as 22 articles and 25 other articles were eliminated because the titles and abstracts did not match the criteria for the topic of discussion. While the eligibility for full-text papers was selected 15 articles and 7 other articles were eliminated because the content of the manuscript did not match the criteria for the topic of discussion. The final result, in the Included stage, 15 papers were obtained 
which were then used as analysis material for literature review.

\subsection{Paper Publication Summary}

This section shows the number of papers on ISOP that have been published. The collected papers are counted until 2021 , there are 101 papers. The number of papers published every year increases exponentially at a fairly high rate of $11.61 \%$. This shows that the field of research that focuses on this topic has developed quite well (Fig. 3). ISOP topics began to develop in 2002, and the highest occurred in 2016 and 2017.

\section{Annual Scientific Production}

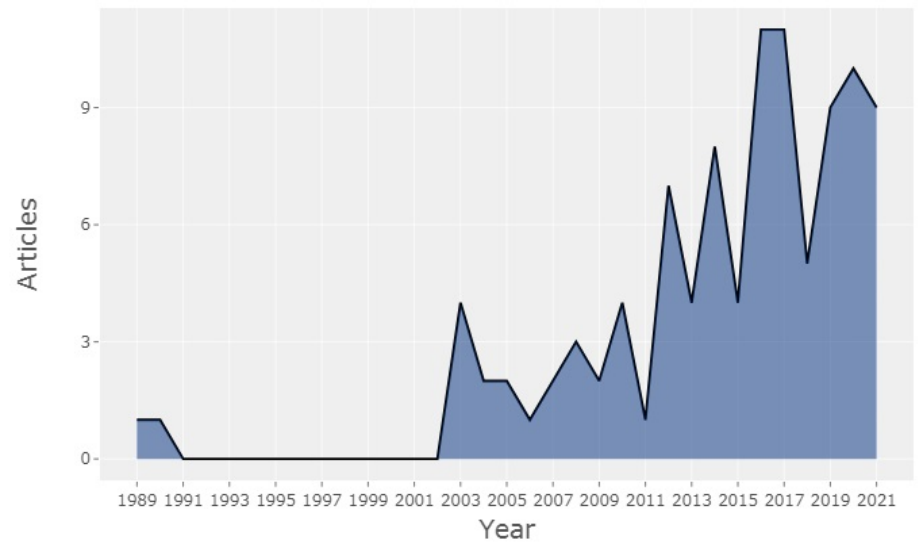

Fig. 3. Growth of papers on ISOP in Google Scholar and Scopus Databases

The following is the main information on research data processing related to ISOP obtained from R-studio programming.

\section{Table 1}

Main information of Papers on ISOP

\section{MAIN INFORMATION ABOUT DATA}

\begin{tabular}{lll}
\hline Timespan & $1989: 2021$ \\
\hline Sources & 84 \\
\hline Documents & 101 \\
\hline Average years from publication & 6.71 \\
Average citations per documents & 186.7 \\
Average citations per year per doc & 7.805 \\
\hline References & 1 \\
\hline
\end{tabular}

Based on Table 1, it can be seen that as many as 84 journal publishers have contributed in publishing 101 documents, with an average of 186.7 citations per document.

\subsection{The Most Produtive Authors}

This section provides information about prolific authors who use ISOP reviews. Overall, 233 authors have covered this topic in their research. A total of 21 authors are single authors and as many as 212 authors consist of Authors and Co-Authors, which can be seen in detail in Table 2.

\section{Table 2}

Author Related to ISOP papers

\begin{tabular}{lll}
\hline & AUTHORS & \\
\hline Authors & 233 \\
Author Appearances & 269 & \\
Authors of single-authored documents & 21 & \\
Authors of multi-authored documents & AUTHORS COLLABORATION & \\
\hline & & 23 \\
\hline Single-authored documents & & \\
Documents per Author & & \\
Authors per Document & 2.31 \\
Co-Authors per Documents & 2.66 \\
Collaboration Index & 2.72 \\
\hline
\end{tabular}

The author's focus is very large in conducting research on the topic of ISOP. The author who is most interested in this topic is Blazewicz J, who has published 9 papers, and in second place is Musial, who has published 7 papers (Fig. 4). 


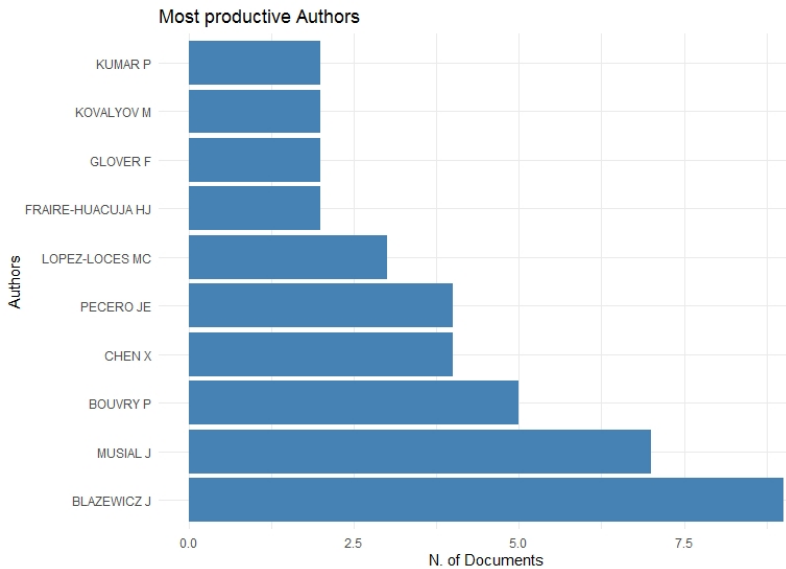

Fig. 4. The Most Produtive Authors about ISOP Topic

Blazewicz has been writing on related topics throughout 2010-2020. Starting from (Błazewicz et al., 2010) which discusses ISOP by minimizing the cost of purchasing goods using the Shop-Enum \& Product-Enum Algorithm method. Furthermore, several other studies were published by developing ISOP topics that paid attention to other things such as discounts, delivery costs, buyer ratings, and others. Looking at the productivity of Authors from year to year, Blazewicz and Musial rank at the top with a frequency of 16 papers during 2010-2020 (Fig. 5).

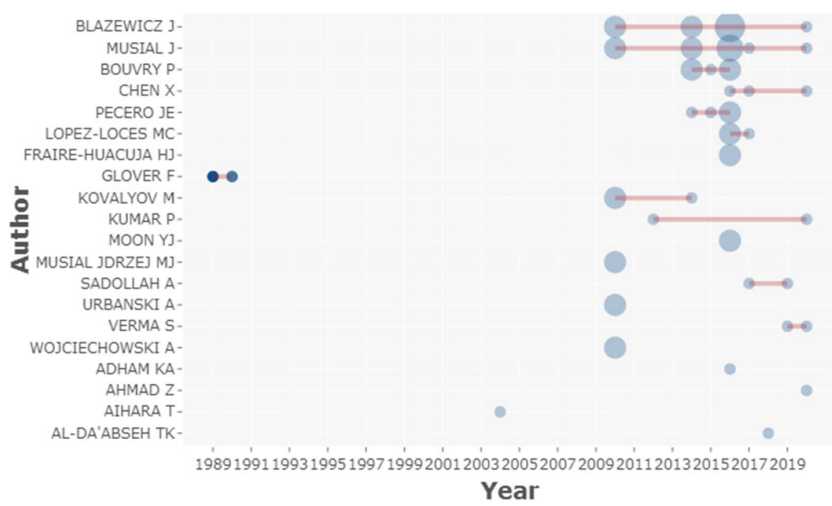

Fig. 5. Top Author Productivity Over Time

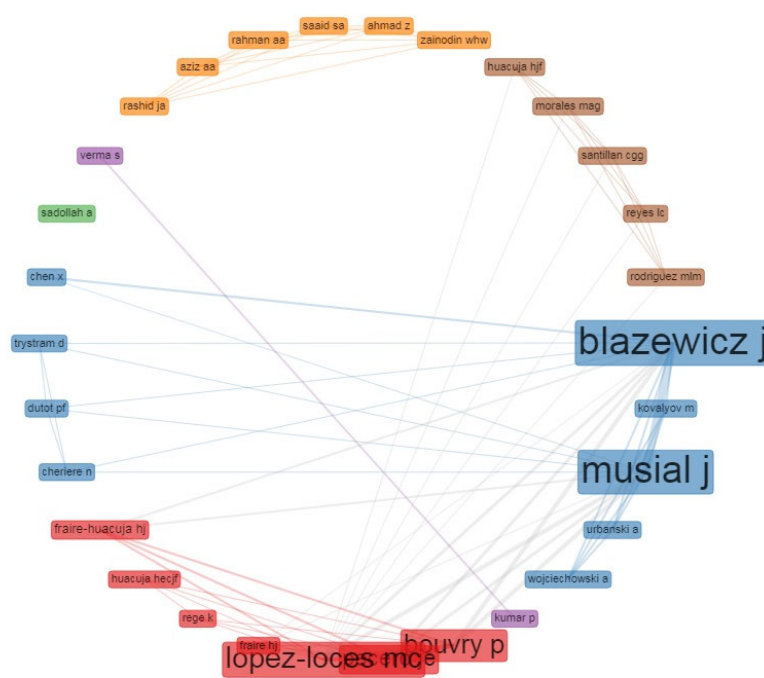

Fig. 6. Collaboration Among the 30 most Productive Authors

Fig. 6 showcases a diverse collaborative network of 30 of the most prolific Authors. Many different colors indicate many 
clusters are formed. Many of these clusters indicate that the level of productivity of the authors is still lacking in forming collaborations with other Authors.

\subsection{Research Citation Pattern}

This section analyzes the citation pattern of papers on ISOP. To date, a total of 18860 papers on this topic have been cited. The 20 most cited papers on this topic are shown in Table 3. Glover F's research received the highest number of citations because it was the earliest published research and the most basic in discussing optimization leading to ISOP optimization. Fig. 7 shows that the highest impact based on the H-index is a research paper written by Blazewicz J. This means that although it is classified as a new research, the quality is very good.

Table 3

Top Ten Most Cited Authors

\begin{tabular}{|c|c|}
\hline Author & Total Citations \\
\hline Glover F & 14916 \\
\hline Forsythe Sm & 1968 \\
\hline Shi B & 1968 \\
\hline Tong X & 241 \\
\hline Card Ja & 184 \\
\hline Chen Cy & 184 \\
\hline Cole St & 184 \\
\hline Dennis C & 176 \\
\hline Jayawardhena C & 176 \\
\hline Morgan A & 176 \\
\hline Wright Lt & 176 \\
\hline Faqih Kms & 148 \\
\hline Jimenez N & 138 \\
\hline Prodanova J & 138 \\
\hline San-Martin S & 138 \\
\hline Bannister F & 108 \\
\hline Connolly $\mathbf{R}$ & 108 \\
\hline Hantula Da & 93 \\
\hline Smith Cl & 93 \\
\hline Blazewicz J & 90 \\
\hline
\end{tabular}

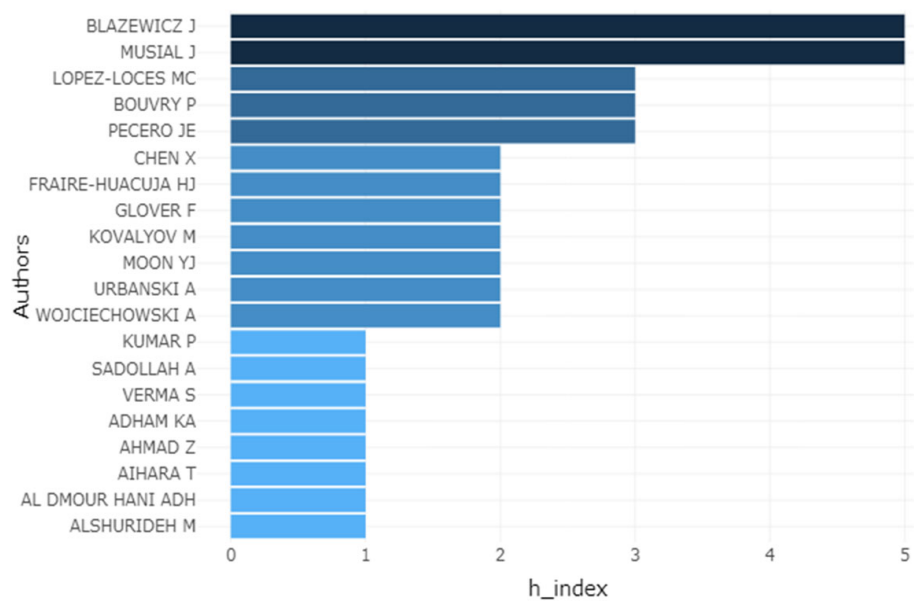

Fig. 7. Author Impact Based on H-Index

\subsection{Main Research Themes}

This section describes a conceptual analysis based on the main research themes that discuss ISOP. This analysis uses the Louvain cluster method (Blondel et al., 2008), which is a simple, efficient and easy-to-apply method to identify objects in a large network. This method introduces a community hierarchy and makes it possible to find sub-communities, sub-subcommunities, and so on. This method is the most widely used to detect data in large networks. The terms used in the writing of the ISOP paper are divided into 5 clusters. The term "ISOP" itself belongs to the orange cluster in Fig.8. The terms contained in the cluster are closely related to the terms in the largest blue cluster. The term that is most closely related to other words is "Internet Shopping". The term is an activity that is the object of research that is always connected to other clusters except the green cluster. Green clusters become new research opportunities if researchers can come up with new terms that can connect with other clusters. 


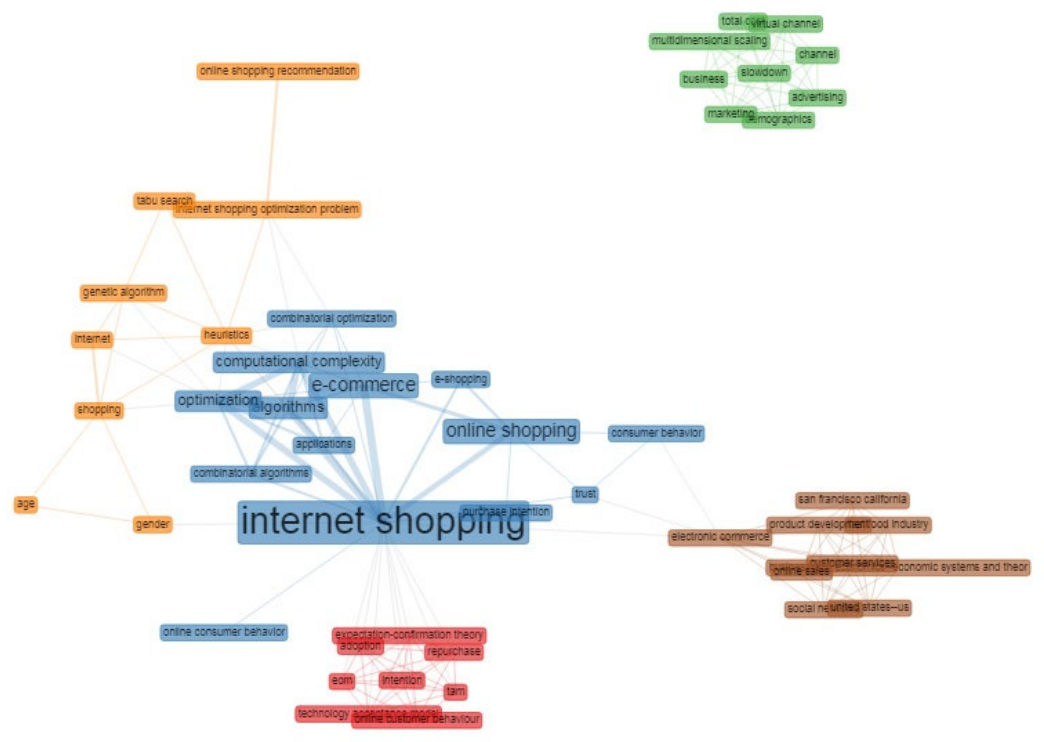

Fig. 8. Clusters of Term Based on Louvain's Method

The next analysis uses term mapping based on the frequency of word trends used in all ISOP papers. Based on Fig. 9 we can find out the trend of the mapped terms based on each year. We can see that in 2015-2017 the most popular topics were discussing topics related to "internet", "shopping", and "Online". Shifted in the next three years the topic began to be associated with the word "Pandemic". That is, online shopping activities during the Covid-19 pandemic began to be raised as a new topic.

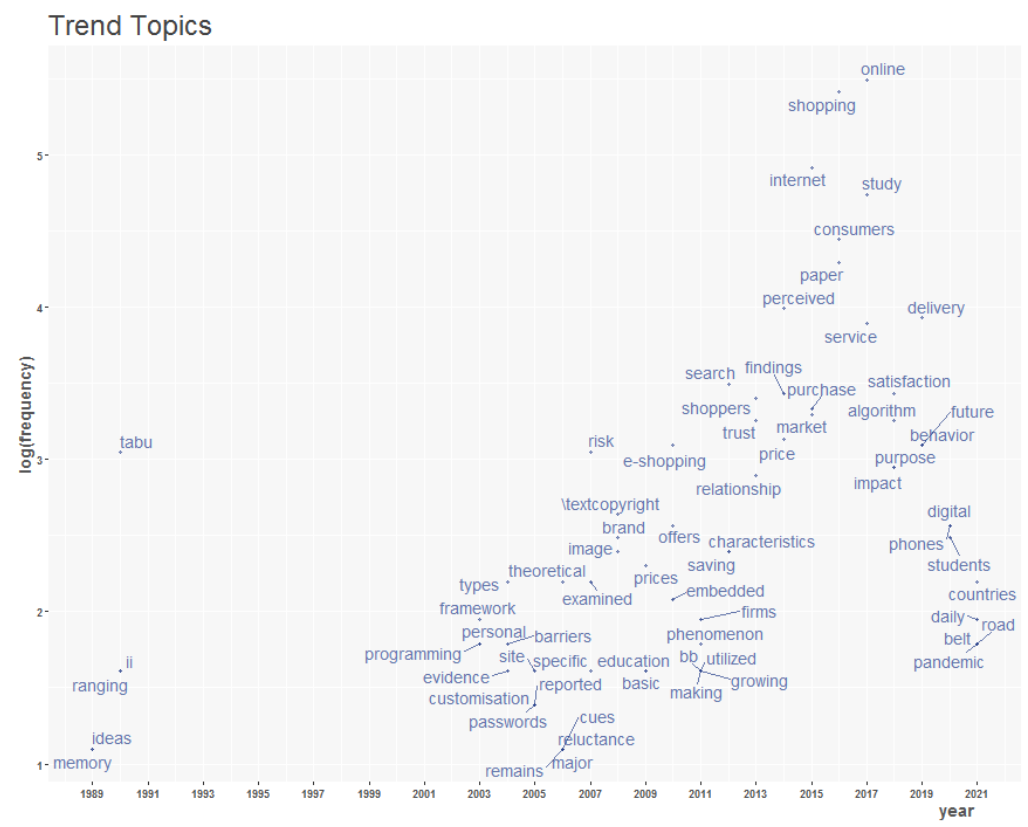

Fig. 9. Trend Topic terms on ISOP Paper

\subsection{State of the art for ARC-ISOP}

State of the art on the topic of ISOP obtained based on PRISMA analysis, there are as many as 15 papers. These papers are research that really focuses on discussing the depth of the ISOP model. ISOP topics that are discussed from time to time are always developing based on the model that is formed and the method used in solving it. The most complicated and difficult part in getting the final solution in ISOP research is when creating an ISOP model resulting from optimization problems involving parameters of uncertainty. Research involving indeterminate parameters has recently been carried out by Chaerani et al. (2021) and Chung (2017). 
Table 4

State of the art for ISOP

\begin{tabular}{|c|c|c|c|c|}
\hline Research & Year & Focus & $\begin{array}{l}\text { Parameter } \\
\text { Uncertainty }\end{array}$ & Methods \\
\hline (Blazewicz et al., 2010) & 2010 & ISOP Optimization & No & Shop-Enum \& Product-Enum Algorithm \\
\hline (Blazewicz et al., 2014) & 2014 & $\begin{array}{l}\text { ISOP Optimization with sensitive } \\
\text { discounts }\end{array}$ & No & Branch and Bound (BB) \\
\hline $\begin{array}{l}\text { (Jedrzej Musial et al., } \\
\text { 2014) }\end{array}$ & 2014 & $\begin{array}{l}\text { ISOP Optimization with sensitive } \\
\text { discounts }\end{array}$ & No & $\begin{array}{l}\text { Greedy Algorithm (GA), Forecasting } \\
\text { Algorithm (FA), Cellular Processing } \\
\text { Algorithm (CPA), MinMin Algorithm, BB }\end{array}$ \\
\hline $\begin{array}{l}\text { (LÓ Pez-Loc ÉS et al., } \\
\text { 2015) }\end{array}$ & 2015 & ISOP Optimization & No & Tabu Search (TS) algorithm \\
\hline $\begin{array}{l}\text { (Lopez-Loces et al., } \\
\text { 2016) }\end{array}$ & 2015 & ISOP Optimization & No & Heuristics Method (HM) \\
\hline (J. Musial et al., 2016) & 2016 & $\begin{array}{l}\text { Comparison of ISOP Optimization Method } \\
\text { Error Values with sensitive discounts }\end{array}$ & No & GA, CPA, MinMin, BB \\
\hline (Blazewicz et al., 2016) & 2016 & $\begin{array}{l}\text { ISOP Optimization with sensitive } \\
\text { discounts }\end{array}$ & No & New Heuristic: New Forecasting \\
\hline $\begin{array}{l}\text { (Jedrzej Musial \& } \\
\text { Lopez-Loces, 2017) }\end{array}$ & 2017 & $\begin{array}{l}\text { ISOP Optimization with sensitive } \\
\text { discounts }\end{array}$ & No & (GA) \\
\hline (Sadollah et al., 2017) & 2017 & $\begin{array}{l}\text { ISOP Optimization with sensitive } \\
\text { discounts }\end{array}$ & No & $\begin{array}{l}\text { GA, Harmony Search (HS) Algorithm, Water } \\
\text { Cycle Algorithm (WCA) }\end{array}$ \\
\hline (J. B. Chung, 2017) & 2017 & ISOP with Delivery Time Constraints & $\begin{array}{l}\text { Delivery Time } \\
\text { Constraints }\end{array}$ & Optimal Pareto Method, Heuristics Method \\
\hline $\begin{array}{l}\text { (J. Chung \& Choi, } \\
\text { 2017) }\end{array}$ & 2017 & $\begin{array}{l}\text { ISOP Optimization with Pairwise } \\
\text { discounts }\end{array}$ & No & Bundle Search Method \\
\hline $\begin{array}{l}\text { (Józefczyk \& } \\
\text { Lawrynowicz, 2018) }\end{array}$ & 2018 & $\begin{array}{l}\text { ISOP Optimization with sensitive } \\
\text { discounts }\end{array}$ & No & TS, Simulated Annealing (SA) \\
\hline (Sayyaadi et al., 2019) & 2019 & ISOP Optimization & No & WCA \\
\hline (Verma et al., 2020) & 2020 & ISOP Optimization & No & GA \\
\hline (Chaerani et al., 2021) & 2021 & ISOP with Uncertain Delivery Time & $\begin{array}{l}\text { Delivery Time } \\
\text { Constraints }\end{array}$ & $\mathrm{ARC}$ \\
\hline
\end{tabular}

\section{Discussion: ARC method in solving ISOP}

The conceptual analysis of terms using the Louvain method presented in Fig. 8 shows that there are 5 clusters. Cluster 1 includes discussions centered on the topic of online shopping/ internet shopping/ e-commerce/ e-shopping which is connected with other terms in the form of complex topics in it. Several keywords in the cluster, namely algorithms, Combinatorial Algorithms, Computational Algorithms and Optimization, are directly related to keywords in Cluster 2, such as "Internet Shopping Optimization Problem", "Tabu Search", "Genetic Algorithm" and "Heuristics" (see Fig. 8). This means that "Internet Shopping" with the goal of "Optimization" (in Cluster 1), is packaged in Cluster 2 as the topic of "Internet Shopping Optimization Problem" using Tabu Search, Genetic Algorithm and Heuristics methods as the solution method. While in Cluster 3, 4, and 5 , it is a study of other fields that are completely unrelated to the topic of Optimization.

Table 5

The Most Popular Keyword

\begin{tabular}{|c|c|c|c|c|}
\hline Cluster 1 & Cluster 2 & Cluster 3 & Cluster 4 & Cluster 5 \\
\hline internet shopping & age & electronic commerce & advertising & ecm \\
\hline consumer behavior & gender & $\begin{array}{l}\text { business and } \\
\text { economics }\end{array}$ & business & $\begin{array}{l}\text { expectation-confirmation } \\
\text { theory }\end{array}$ \\
\hline online shopping & shopping & customer services & channel & $\operatorname{tam}$ \\
\hline trust & heuristics & fast food industry & demographics & technology acceptance model \\
\hline e-commerce & $\begin{array}{l}\text { internet shopping optimization } \\
\text { problem }\end{array}$ & online sales & marketing & adoption \\
\hline algorithms & online shopping recommendation & product development & $\begin{array}{l}\text { multidimensional } \\
\text { scaling }\end{array}$ & intention \\
\hline $\begin{array}{l}\text { combinatorial } \\
\text { algorithms }\end{array}$ & tabu search & $\begin{array}{l}\text { san francisco } \\
\text { california }\end{array}$ & slowdown & online customer behaviour \\
\hline $\begin{array}{l}\text { computational } \\
\text { complexity }\end{array}$ & internet & social networks & total cost & repurchase \\
\hline optimization & genetic algorithm & united states--us & virtual channel & \\
\hline \multicolumn{5}{|l|}{$\begin{array}{l}\text { online consumer } \\
\text { behavior }\end{array}$} \\
\hline \multicolumn{5}{|l|}{ e-shopping } \\
\hline \multicolumn{5}{|l|}{ applications } \\
\hline \multicolumn{5}{|l|}{ purchase intention } \\
\hline $\begin{array}{l}\text { combinatorial } \\
\text { optimization }\end{array}$ & & & & \\
\hline
\end{tabular}


In the blue cluster (Cluster 1), there is the main term, namely the term "Internet Shopping", which is followed by other sub keywords, the majority of which are the same terms as "Internet Shopping", namely "E-Shopping", "Online Shopping", and "E-Commerce". This can be interpreted that the object of research in previous studies, uses different terms but has the same meaning. The orange cluster (Cluster 2) consists of the main term "ISOP" followed by other sub terms such as "Genetic Algorithm", "Heuristics", and "Tabu Search". This means that the most frequently used methods in solving ISOP optimization solutions are Genetic Algorithm, Heuristics, and Tabu Search methods. The ARC method in solving ISOP problems has not been widely used. This can be seen from the relationship between the terms in the clusters that are formed, there is no ARC term. The statement that there are not many studies using ARC in the ISOP, is supported by the resulting State of the Art. State of the Art shows that there is only one study using the ARC method in the ISOP. The study was published by (Chaerani et al., 2021 ) in 2021 and is the most recent ISOP study.

\section{Conclusions}

The analysis in this research shows that the topic of ISOP has become a topic that is widely discussed. Papers that have been published have made a great contribution to today's authors. Within 10 years, the research has grown to cover 101 papers and this number is growing about $11.61 \%$ every year. Based on the PRISMA analysis, 101 papers were obtained, there were only 15 papers that discussed ISOP in depth and completed the optimization model with fairly good methods. The impact of ISOP topics is very valuable in the field of research. This can be seen from the number of citations and the H-index scale collected from this research. In addition, the author's productivity and collaboration in writing ISOP topics is very good, whose research development began in 2010. The term cluster analysis shows that the ARC method has not been widely used in ISOP. The application of the ARC method to the ISOP only appeared in research published in 2021. The State of the Art results also show how the development of ISOP research and its methods have emerged in the last 10 years. The ARC method in the ISOP is a very feasible method for further development, considering that the last published research is only limited to discussing the derivation of the model. This creates many opportunities in making new research on ARC in ISOP with all their complexities. For example the development of new parameters such as discount parameters, store ratings, consumer reviews, and others. In addition, mathematical characterization of the ARC-ISOP can also be carried out, including mathematical proof of convex optimization and analysis of the robustness level of the ARC method.

\section{Acknowledgments}

This research is supported by LPDP (Lembaga Pengelola Dana Pendidikan) Ministry of Finance, Republic of Indonesia to the first author, who is the Indonesian LPDP Scholarship Recipient for the Mathematics Masters Program at Padjadjaran University. The second and third authors are supported by the Basic Research Scheme of the Ministry of Research, Technology and Higher Education of the Republic of Indonesia in 2021 based on contracts number 9/E1/KP/PTNBH/2021 and 1027/UN6.3.1/PT.00/2021.

\section{References}

Aria, M., \& Cuccurullo, C. (2017). bibliometrix: An R-tool for comprehensive science mapping analysis. Journal of Informetrics, 11(4), 959-975. https://doi.org/10.1016/j.joi.2017.08.007

Ben-Tal, A., Ghaoui, L. El, \& Nemirovski, A. (2009). Robust optimization. In Robust Optimization. books.google.com. https://doi.org/10.1016/s1474-6670(17)42591-2

Ben-Tal, A., \& Nemirovski, A. (2002). Robust optimization--methodology and applications. Mathematical Programming, 92(3), 453-480.

Bertsimas, D., \& Tsitsiklis, J. N. (1997). Introduction to Linear Optimization (ch1-5). In Introduction to Linear Optimization (Vol. 6). Athena Scientific Belmont, MA.

Billionnet, A., Costa, M. C., \& Poirion, P. L. (2014). 2-stage robust MILP with continuous recourse variables. Discrete Applied Mathematics, 170, 21-32. https://doi.org/10.1016/j.dam.2014.01.017

Blazewicz, J., Bouvry, P., Kovalyov, M. Y., \& Musial, J. (2014). Erratum to: Internet shopping with price-sensitive discounts (4OR-Q J Oper Res (2014) 12, (35-48), 10.1007/s10288-013-0230-7). In 4or (Vol. 12, Issue 4, pp. 403-406). https://doi.org/10.1007/s10288-014-0271-6

Blazewicz, J., Cheriere, N., Dutot, P. F., Musial, J., \& Trystram, D. (2016). Novel dual discounting functions for the Internet shopping optimization problem: new algorithms. Journal of Scheduling, 19(3), 245-255. https://doi.org/10.1007/s10951014-0390-0

Błazewicz, J., Kovalyov, M., Musiał, J., Urbański, A., \& Wojciechowski, A. (2010). Internet shopping optimization problem. International Journal of Applied Mathematics and Computer Science, 20(2), 385-390. https://doi.org/10.2478/v10006010-0028-0

Blondel, V. D., Guillaume, J. L., Lambiotte, R., \& Lefebvre, E. (2008). Fast unfolding of communities in large networks. Journal of Statistical Mechanics: Theory and Experiment, 2008(10), P10008. https://doi.org/10.1088/17425468/2008/10/P10008

Chaerani, D., Rusyaman, E., Mahrudinda, Marcia, A., \& Fridayana, A. (2021). Adjustable robust counterpart optimization 
model for internet shopping online problem. Journal of Physics: Conference Series, 1722(1), 12074. https://doi.org/10.1088/1742-6596/1722/1/012074

Chen, X., \& Zhang, Y. (2009). Uncertain linear programs: Extended affinely adjustable robust counterparts. Operations Research, 57(6), 1469-1482. https://doi.org/10.1287/opre.1080.0605

Chung, J. B. (2017). Internet shopping optimization problem with delivery constraints. Journal of Distribution Science, 15(2), 15-20. https://doi.org/10.15722/jds.15.2.201702.15

Chung, J., \& Choi, B. (2017). Complexity and algorithms for optimal bundle search problem with pairwise discount. Journal of Distribution Science, 15(7), 35-41. https://doi.org/10.15722/jds.15.7.201707.35

Glover, F. (1989). Tabu search-part I. ORSA Journal on Computing. https://pubsonline.informs.org/doi/abs/10.1287/ijoc.1.3.190

Józefczyk, J., \& Ławrynowicz, M. (2018). Heuristic algorithms for the Internet shopping optimization problem with price sensitivity discounts. Kybernetes, 47(4), 831-852. https://doi.org/10.1108/K-07-2017-0264

LÓ Pez-Loc ÉS, M. C., Rege, K., Pecero, J. E., Bouvry, P., \& Huacuja, Héc. J. F. (2015). Trajectory metaheuristics for the internet shopping optimization problem. Studies in Computational Intelligence, 601, 527-536. https://doi.org/10.1007/978-3-319-17747-2_41

Lopez-Loces, M. C., Musial, J., Pecero, J. E., Fraire-Huacuja, H. J., Blazewicz, J., \& Bouvry, P. (2016). Exact and heuristic approaches to solve the Internet shopping optimization problem with delivery costs. International Journal of Applied Mathematics and Computer Science, 26(2), 391-406. https://doi.org/10.1515/amcs-2016-0028

Moher, D., Liberati, A., Tetzlaff, J., \& Altman, D. G. (2009). Preferred reporting items for systematic reviews and metaanalyses: the PRISMA statement. Journal of Clinical Epidemiology. https://doi.org/10.1016/j.jclinepi.2009.06.005

Musial, J., Pecero, J. E., Lopez-Loces, M. C., Fraire-Huacuja, H. J., Bouvry, P., \& Blazewicz, J. (2016). Algorithms solving the Internet shopping optimization problem with price discounts. Bulletin of the Polish Academy of Sciences: Technical Sciences, 64(3), 505-516. https://doi.org/10.1515/bpasts-2016-0056

Musial, Jedrzej, \& Lopez-Loces, M. C. (2017). Trustworthy Online Shopping with Price Impact. Foundations of Computing and Decision Sciences, 42(2), 121-136. https://doi.org/10.1515/fcds-2017-0005

Musial, Jedrzej, Pecero, J. E., Lopez, M. C., Fraire, H. J., Bouvry, P., \& Blazewicz, J. (2014). How to efficiently solve internet shopping optimization problem with price sensitive discounts? ICE-B 2014 - Proceedings of the 11th International Conference on e-Business, Part of ICETE 2014 - 11th International Joint Conference on e-Business and Telecommunications, 209-215. https://doi.org/10.5220/0005112602090215

Sadollah, A., Gao, K., Barzegar, A., \& Su, R. (2017). Improved model of combinatorial Internet shopping optimization problem using evolutionary algorithms. In 2016 14th International Conference on Control, Automation, Robotics and Vision, ICARCV 2016. https://doi.org/10.1109/ICARCV.2016.7838660

Sayyaadi, H., Sadollah, A., Yadav, A., \& Yadav, N. (2019). Stability and iterative convergence of water cycle algorithm for computationally expensive and combinatorial Internet shopping optimisation problems. Journal of Experimental and Theoretical Artificial Intelligence, 31(5), 701-721. https://doi.org/10.1080/0952813X.2018.1549109

Stovold, E., Beecher, D., Foxlee, R., \& Noel-Storr, A. (2014). Study flow diagrams in Cochrane systematic review updates: An adapted PRISMA flow diagram. In Systematic Reviews (Vol. 3, Issue 1). https://doi.org/10.1186/2046-4053-3-54

Templeton, A. (2020). A bibliometric analysis of Atangana-Baleanu operators in fractional calculus. Alexandria Engineering Journal, 59(4), 2733-2738. https://doi.org/10.1016/j.aej.2020.05.016

Urbanek, S., Bibiko, H.-J., \& Stefano, M. L. (2014). R: a language and environment for statistical computing. The R Foundation for Statistical Computing (4.0.2). https://www.r-project.org

Verma, S., Sinha, A., Kumar, P., \& Maitin, A. (2020). Optimizing online shopping using genetic algorithm. Proceedings - 3rd International Conference on Information and Computer Technologies, ICICT 2020, $271-275$. https://doi.org/10.1109/ICICT50521.2020.00048

Yanıkoğlu, İ., Gorissen, B. L., \& den Hertog, D. (2019). A survey of adjustable robust optimization. European Journal of Operational Research, 277(3), 799-813. https://doi.org/10.1016/j.ejor.2018.08.031 
(C) 2022 by the authors; licensee Growing Science, Canada. This is an open access article distributed under the terms and conditions of the Creative Commons Attribution (CC-BY) license (http://creativecommons.org/licenses/by/4.0/). 